\title{
Lugares-comums e interpretação alegórica: considerações sobre a elaboração da literatura medieval a partir de um roman do século XIV
}

Jaqueline Silva de Macedo ${ }^{1}$

Resumo: Durante a querela entre o rei da França Filipe o Belo (1285-1314) e o papas Bonifácio VIII (1294-1303) e Clemente V (1305-1314), foram produzidos textos que discutiam, em termos gerais, o direito e o dever de sobrepujar o seu adversário em poder como liderança espiritual e material. Um deles é o Roman de Fauvel, em sua fase final. Propomos esboçar o teor desta fonte considerando ostopoi(lugares-comuns)percorridos por ela. Esta abordagem nos ajuda a analisar o tipo de registro textual e o contexto que possibilitou sua construção na sociedade medieval nos círculos principescos.

Palavras-chave: França medieval. Topoi. Roman de Fauvel.

Abstract: During the conflict between the king of France Philip the Fair (1285-1314) and the popes Boniface VIII (1294-1303) and Clement V (13051314), texts has been produced which discussed, in general terms, the right and duty to surpass their adversary in power as spiritual and material leadership. One of them is the Roman de Fauvel, in its final phase. We propose to sketch the content of this source considering the common places covered by it. This approach will help us to analyze the type of textual record and the context that allowed its construction in medieval society in princely circles.

Keywords: Medieval France. Topoi. Roman de Fauvel.

${ }^{1}$ Discente do Programa de Pós-Graduação em História da Escola de Filosofia, Letras e Ciências Humanas da Universidade Federal de São Paulo (UNIFESP). E-mail: macedo.js@bol.com.br.

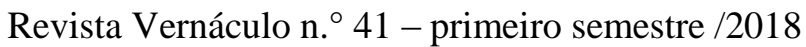

ISSN 2317-4021 
Examinar os vestígios do passado não é tarefa fácil para o historiador. A célebre frase de Certeau, "em história tudo começa com o gesto de separar, de reunir, de transformar em "documentos" certos objetos distribuídos de outra maneira" ${ }^{2}$ continua presente na prática historiográfica atual. É inevitável ainda ao pesquisador recortar o tempo e o espaço a serem analisados, mas também a abordagem que se fará desse documento. Afinal, não é possível um único indivíduo abarcar todas as potencialidades do documento e do fenômeno histórico "escolhido", o que possibilita a contínua renovação dos seus discursos.

É por meio dos vestígios, que não revelam de modo algum imediatamente o passado, mas dependem das perguntas feitas pelo historiador; essa parcialidade, advinda do seu ponto de vista que embora diferente de outros faz chegar a verossimilhança histórica ${ }^{3}$, que se constrói a interpretação do documento, e para isso, as ferramentas escolhidas que fazem parte da abordagem citada acima é fundamental no exame e elaboração da história. ${ }^{4}$

${ }^{2}$ CERTEAU, M. A Escrita da história/Michel de Certeau; tradução de Maria de Lourdes Menezes;*revisão técnica [de] Arno Vogel. - Rio de Janeiro: Forense Universitária, 1982, p. 81.

${ }^{3}$ Recomendamos o artigo Sinais: raízes de um paradigma indiciário. In: GINZBURG, C. Mitos, emblemas, sinais: morfologia e história. Trad. Federico Carotti. São Paulo: Companhia das Letras, 1989, p. 143-180. O micro-historiador perscruta o método indiciário na descoberta do passado através da arte divinatória, da crítica de arte e na solução de crimes relacionando com o método próprio da prática historiográfica sobretudo a partir do século XIX.

${ }^{4}$ Certeau se refere ao exame, a análise como prática, e à escrita, seu resultado, como discurso. A relação da análise com a escrita, uma "produção": CERTEAU, M. A Escrita da história/Michel de Certeau; tradução de Maria de Lourdes Menezes;*revisão técnica [de] Arno Vogel. - Rio de Janeiro: Forense Universitária, 1982, p. 32.

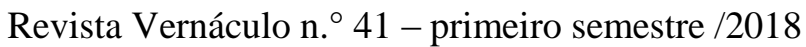

ISSN 2317-4021 
Feitas essas ressalvas, o recorte temporal que delimitamos, bem como a seleção de nossas fontes produzem um sentido e nos dão uma certo alívio em vista das inúmeras possibilidades de análises que não somos capazes de abranger em uma dissertação ou tese, menos ainda em um artigo. Nesse viés, nosso objetivo no presente trabalho é esboçar algumas considerações acerca de nossa fonte de pesquisa atual, isto é, o Roman de Fauvel, poema produzido entre os anos de 1310 e 1314 na França, atentando para a sua interpretação de acordo com algumas abordagens no que concerne a literatura e história medieval nos auxiliando na compreensão relacional entre lugares-comuns e criatividade medieval, além da discussão entre os poderes exercidos pela Igreja e pelo monarca, evitando possíveis equívocos interpretativos.

Para isso, buscamos nas análises de João Adolfo Hansen, ${ }^{5}$ Erich Auerbach, ${ }^{6}$ Ernst Curtius $^{7}$ e Umberto $\operatorname{Eco}^{8}$ a interpretação alegórica figural da história realizada no medievo e transposta na literatura. Paul Zumthor ${ }^{9}$ e Halász ${ }^{10}$ contribuem à nossa análise no que

${ }^{5}$ HANSEN, J. A. Alegoria. Construção e interpretação da metáfora. São Paulo: Atual, 1986. HANSEN, J. A. A sátira e o engenho. Gregório de Matos e a Bahia do século XVII. São Paulo: Companhia das Letras: Secretaria do Estado da Cultura, 1989.

${ }^{6}$ AUERBACH, E. Figura. São Paulo: Editora Ática, 1997.

${ }^{7}$ CURTIUS, E. R. Literatura europeia e Idade Média Latina. Trad. Paulo Ronai e Teodoro Cabral. Col. Clássicos. 3 ed. São Paulo: EDUSP, 1996.

${ }^{8}$ ECO, U. Arte e beleza na estética medieval. Trad. Mario Sabino. Rio de Janeiro: Record, 2010.

${ }^{9}$ ZUMTHOR, P. Essai de lapoétiquemédiévale. coll. Poétique. Paris: ÉditionsduSeuil, 1972. ZUMTHOR, P. A letra e a voz: A "literatura" medieval. Trad. Amálio Pinheiro (Parte I) e Jerusa Pires Ferreira (Parte II). São Paulo: Companhia das Letras, 1993. Revista Vernáculo n. ${ }^{\circ} 41$ - primeiro semestre /2018 
concerne a estrutura do roman e sua relação com o autor, bem como Armand Strubel responsável pela última edição do Roman de Fauvel. ${ }^{11}$

Entretanto, não pretendemos uma análise essencialista da fonte e por isso buscamos apoio no contexto que possibilitou a produção do roman. Ou seja, o reinado de Filipe o Belo (1285-1314) e a querela que travou com a Igreja no intuito de legitimar o poder laico frente ao espiritual. Por outro lado, não intentamos considerar o roman apenas como uma obra circunstancial como nos adverte Strubel. ${ }^{12}$ Buscamos nos desvios e "falhas" entre o discurso do documento e os eventos históricos nossa própria interpretação sobre a discussão das esferas de poder do período, o que não pode ser alcançado se ignoramos as normas do feitio literário ou os eventos vividos. Assim, perpassamos prioritariamente alguns trabalhos de Jean Favier, ${ }^{13}$ Marcel Pacaut, ${ }^{14}$

ZUMTHOR, P. Introdução à poesia oral. Trad. Jerusa Pires Ferreira, Maria Lúcia Diniz Pochat e Maria Inês de Almeida. São Paulo: Editora Hucitec, 1997.

10 HALÁSZ, K. Images d'auteurdansleromanmédieval (XII ${ }^{e}$ et XIII siècles).KossuthLajosTudományegyetem: Debrecen, 1992.

${ }^{11}$ Utilizamos a edição bilíngue elaborada por Armand Strubel que abrange não apenas o poema, mas as adições feitas posteriormente que trataremos a seguir. Não há tradução do poema em português, por isso os trechos citados aqui terão tradução livre conforme o original. A tradução em francês moderno de Strubel nos auxiliam somente quando houve dúvidas quanto ao melhor termo a ser traduzido para o português. Le roman de Fauvel. Édition, traductionetprésentation par Armand Strubel. Le livre de poche, 2012.

${ }^{12}$ Le roman de Fauvel. Édition, traductionetprésentation par Armand Strubel. Le livre de poche, 2012.

${ }^{13}$ FAVIER, J. Philippe Le Bel. Fayard, 1978.

${ }^{14}$ PACAUT, M. Histoire de lapapauté. De l'origineauconcile de Trente. Fayard, 1976. Revista Vernáculo n. ${ }^{\circ} 41$ - primeiro semestre /2018 
Walter Ullmann ${ }^{15}$ eJulienThéry, ${ }^{16}$ porém indicando em nota outros pesquisadores que versam sobre o assunto.

\section{Roman de Fauvel:}

Nos últimos cinco anos do reinado de Filipe o Belo (13101314) foi escrito por um notário clérigo da chancelaria real um poema satírico em duas partes. O notário Gervais de Bus terminou o primeiro livro em 1310 e o segundo em 1314 conforme o próprio poeta assinou, estratégia comum na Idade Média indicando que o comprador tinha em mãos a obra completa. ${ }^{17}$ Os dois livros com $3280^{18}$ versos explora a

${ }^{15}$ ULLMANN, W. A Short History of the Papacy in the Middle Ages. London: Taylor \& Francis e-Library, 2005.

${ }^{16}$ THÉRY, J. Philippe le Bel, pape en son royaume. L'histoire, Sophia Publications, 2004, pp. 14-17. Disponíve lem<halshs-00219769>. Acessoem 03/ago/2016.; THÉRY, J. Le pionnier de la théocratieroyale: Guillaume de Nogaretet les conflits de Philippe le Bel avec la paupaté; In: MOREAU, B. (dir.) Unlangodocienauservice de lamonarchiecapétienne. Nîmes: Lucie Éditions, 2012, p. 101-128.; THÉRY, J. Lesécritures ne peuvent mentir. Note preliminairepourl'étudedesréférencesauxautoritésréligieusesdanslestextes de Guillaume de Nogaret. In: MOREAU, B; THÉRY-ASTRUC, J. (éd). La royautécapétienne et leMidiautemps de Guillaume de Nogaret. ActesduColloque de Montpellier et Nîmes (29 et 30 novembre 2013), Nîmes: Éditions de laFenestrelle, 2015, p. 243-248.

${ }^{17}$ CURTIUS, E. R. Literatura europeia e Idade Média Latina. Trad. Paulo Ronai e Teodoro Cabral. Col. Clássicos. 3 ed. São Paulo: EDUSP, 1996. Outros escritos considerados políticos foram produzidos nessa época como a Disputatiointerclericum etmilitem e Quaestio in utramque partem, além de pequenos versos repreendendo a conduta do papa: Ecclesiaenavistitubât, regniquiaclavisErrât; Rex, Papa, factišuntunica capa; Haecfaciunt do, des, Pilatus hic, alter Herodes. MAURICE, J.Une satire contre Philippe le Belet Clément V. In: Bibliothèque de l'école des chartes. 1908, tome 69. pp. 280-281. Disponível em: <http://www.persee.fr/web/revues/home/prescript/article/bec_0373 6237_1908_num_69_1_448336>. Acesso em: 30/abr/2017.

${ }^{18} \mathrm{O}$ primeiro livro compõe 1226 versos e o segundo 2054 versos.

Revista Vernáculo n. ${ }^{\circ} 41$ - primeiro semestre /2018

ISSN 2317-4021 
versificação octossilábica em rima plana e recorre à langue d'oil, falada no norte do reino e aos dialetos próximos para sua composição. ${ }^{19}$

No primeiro livro o poeta se restringe à descrição do anti-herói Fauvel, um cavalo ambicioso que usa sua natureza enganadora para sair do estábulo onde vivia próximo ao palácio real e se assenta no trono francês como rei submetendo todos o estats sociais à sua vontade. À descrição do personagem segue-se a demonstração dessa submissão ao cavalo pelas pessoas do reino não importando sua posição; se clérigo ou laico, independentemente se nobre ou súdito comum, todos estão bestournés, bestializados, isto é, todos agem de maneira contrária ao que foi estabelecido por Deus na criação. Os homens que deveriam dominar e ser servidos pelos animais estão se sujeitando a eles. No poema, a sujeição está ligada à bajulação feita pelos humanos em busca de favores concedidos pelo cavalo e nesse sentido o pecado não recai apenas ao animal, mas na ambição própria do homem. A expressões limpar (torcher) e esfregar (froter) são presentescomo escovar o dito cavalo. $^{20}$

Já no segundo livro a atenção se volta não à situação da sociedade no plano material, mas à natureza de Fortuna a quem Fauvel

${ }^{19} \mathrm{O}$ poema octossilábico organiza os versos em oito sílabas fonéticas cada, mantendo dessa forma um ritmo próprio para a atuação do intérprete. A rima plana também tinha o objetivo ornamental e interpretativo, pois, em cada estrofe se organizava os dois primeiros versos com uma determinada rima final e os dois últimos com outra rima. Assim temos logo nos primeiros versos do roman: De Fauvel que tantvoitorcher Doucement, sanzluiescorcher, ISui entrezenmerencolie, $\backslash$ Pourcequ'est beste si polie (Roman de Fauvel, vv. 1-4, grifo nosso).

${ }^{20}$ Le roman de Fauvel. Édition, traductionetprésentation par Armand Strubel. Le livre de poche, 2012. vv. 1, 21, et seq.

Revista Vernáculo n. ${ }^{\circ} 41$ - primeiro semestre $/ 2018$

ISSN 2317-4021 
pretende se casar. O poema começa com uma descrição do assento real, do palácio e da corte de Fauvel; segue-se a viagem a Macrocosmo onde Fortuna habita e que Fauvel aconselhado por sua corte se dirige para pedir a deusa em casamento. A partir da declaração de Fauvel, Fortuna protagoniza um longo discurso de auto-definição e desprezo por Fauvel. Nesse sentido, os versos reclamam uma veia mais filosófica e apocalíptica que o primeiro, embora no fim do livro de 1310 a associação de Fauvel com o Anticristo se evidencia. ${ }^{21}$

Entre os anos de 1316 e 1318 o poema foi ampliado reunindo além do poema, imagens ilustrando a narrativa, músicas em latim e uma crônica métrica. As adições feitas transformam o poema em um documento com pelo menos o triplo do tamanho contando com mais 2500 versos. ${ }^{22}$ Também produzido na chancelaria real agora sob o reinado do filho de Filipe IV, Luís X, o manuscrito conhecido como BnFfr 146 e disponível na BibliothèqueNationale de France é singular por seu caráter luxuoso ainda que não seja um documento oficial. ${ }^{23}$

Há uma certa tradição nas pesquisas no exterior referente a este manuscrito. Se explora os lais, os motets, a iconografia, e mesmo o

${ }^{21}$ Segundo as Escrituras, o Anticristo aparecerá na Terra antes da segunda vinda de Jesus, efetuando sinais para enganar a humanidade e se opondo a toda noção de Deus para que acreditem que o melhor provém dele, o Anticristo, que na verdade é enviado pelo Diabo. Cf. II Tessalonicenses: 2: 1-17.

${ }^{22}$ Le roman de Fauvel. Édition, traductionetprésentation par Armand Strubel. Le livre de poche, 2012.

${ }^{23}$ Roman de Fauvel.BiliothèqueNationale de France, Gallica. Disponível em <http://gallica.bnf.fr/m/ark:/12148/btv1b8454675g/f33.item>.

Acessoem: 24/mar/2017.

Revista Vernáculo n. ${ }^{\circ} 41$ - primeiro semestre /2018

ISSN 2317-4021 
conjunto das três artes. ${ }^{24}$ Jean-Claude Mühlethaler é um dos poucos que explora o poema original, dando atenção à sátira do primeiro livro. ${ }^{25} \mathrm{O}$ poema se tornou parte do Bnffr 146 e não o oposto ${ }^{26}$ e o documento possibilita diversas abordagens para além das apontadas. O próprio perfil político do poema pode ser interpretado tanto como um espelho de príncipe (regimemprincipis) nos moldes de Gilles de Roma como um conselho ao rei (admonitio regum) à maneira do manuscrito. ${ }^{27}$

No Brasil, o poema mais estudado pelos literários e pelos historiadores é o longo Roman de la Rose escrito décadas antes do Roman de Fauvel e que o influenciou, ${ }^{28}$ mas sua estrutura poética não se assemelha à sátira densa do nosso roman. O Roman de Fauvel ainda não foi objeto de estudos historiográficos no Brasil, $^{29}$ assim, a

${ }^{24}$ Ver: DILLON, Emma. Medieval Music-Making and the Roman de Fauvel. New Perspectives in Music History and Criticism. Cambridge and New York: Cambridge University Press, 2002.;SHEN-WEI, T.H. Musical "Beastliness" in the Roman de Fauvel(BN fr. 146): Chaillou's "addicions" and Sensory Danger. 2010. 233p. Tese (DoutoradoemMúsica). The Honors College, Wesleyan University, 2010.

${ }_{25}$ MÜHLETHALER, J-C. Fauvelaupouvoir. Lire la satire médiévale. Paris: Champion (Nouvelle bibliothèque du MoyenÂge, 26), 1994.

${ }^{26}$ Le roman de Fauvel. Édition, traductionetprésentation par Armand Strubel. Le livre de poche, 2012.

${ }^{27}$ Ibidem, 2012.

p. 75-76.Passim.

${ }^{28} \mathrm{O}$ Roman de la Rose foi uma das obras mais lidas na Idade Média. Composta por duas partes, a primeira contendo 4058 versos foi escrita por Guillaume de Lorris (1200-1260) em 1225-1235; a segunda escrita entre 1268 e 1285 por Jean de Meun (1240-1304) possui 17.724 versos, ambas as partes em versos octossilábicos. Os personagens do Roman de la Rose também são personificações de vícios e virtudes como a Razão, o Amor, o Ciúme e a Inveja, porém, o motivo narrativo da primeira parte é lírica, enquanto a segunda, de autoria de Jean de Meun é satírica.

${ }^{29} \mathrm{O}$ único trabalho que encontramos no Brasil acerca do Roman de Fauvel é a tese de Fernando José Carvalhaes Duarte em 2000 defendido na área de comunicação com

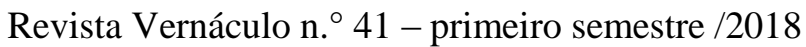


oportunidade que temos é de apresentar esse rico documento que ultrapassa à literatura, extremamente importante como cultura, mas que possibilita também uma análise histórica sobre o discurso dos poderes em conflito durante o reinado de Filipe o Belo e a partir de ações do período em que o poema foi escrito. Por isso nosso recorte nos limita a análise do poema produzido entre 1310-1314, não podendo nos estender à coroação de seu filho e às implicações que o reino sofreu e que são trabalhados no ms. 146.

Dessa forma, o poema original nos basta por enquantocomo basepara traçarmos uma gama de particularidades encontradas na literatura medieval e da maneira como a sociedade e a história eram interpretados pelos homens do período, nos ajudando a não fazermos apenas simples correspondências entre elas, mas buscarmos os desvios nas normas da literatura que nos ajudem a interpretar os fenômenos históricos acerca da legitimação de poderes em fins do século XIII e início do século XIV.

\section{Roman:da diversão ao ensino}

O roman, assim como outras formas de escrita lúdica(lais, as chansons de geste e as ballades), aparece nas sociedades medievais no mesmo período em que houve a estabilização das universidades, o

ênfase na musicologia do documento. Infelizmente não tivemos acesso ao trabalho, apenas ao resumo disponibilizado pelo banco de teses da Pontifícia Universidade Católica de São Paulo onde foi elaborada. O silêncio de Fortuna: artefato e performance no Roman de Fauvel. 2000. 319 f. Tese (Doutorado em Comunicação)Pontifícia Universidade Católica de São Paulo, 2000.

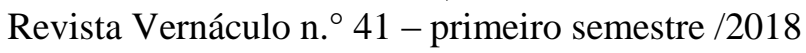

ISSN 2317-4021 
aumento das viagens por comércio ou peregrinação nas Cruzadas e a consolidação das línguas vernáculasentre os século XI e XII. ${ }^{30}$ Mais que coincidências, esses fatores contribuíram para o aumento da produção textual acadêmica e lúdica e vieram da mesma fonte: as universidades. Ernst Curtius lembra que o exercício poético era estimulado nas escolas elementares e posteriormente à formação universitária. Os clérigos que não conseguissem lugar nos espaços eclesiásticos (abadias, dioceses, etc.), tentavam a sorte nas cortes por meio da poesia ou ainda por meio de doações e favores fora delas.

Por que se escrevia poesia? Porque se aprendia na escola. Um grande número de autores medievais escrevia poesia porque era necessário sabê-la para se apresentar como clericus e litteratus $;^{31}$ para compor saudações, epitáfios, petições, dedicatórias, assim granjear o favor dos poderosos ou corresponder-se com pessoas de situação igual; também por amor ao vil metal. Pode-se ensinar e aprender a escrever poesias; é trabalho e matérias escolares. ${ }^{32}$

${ }^{30}$ GAUNT, S., KAY, S. Introduction. In: GAUNT, S., KAY, S (éd). The Cambridge companion to Medieval frenchliterature.Cambridge University Press, 2008, p. 13. O Tratado de Cabreros em 1206 firmado entre Castela e Leão na língua castelhana, constitui segundo Smith o primeiro documento oficial em vernáculo, sendo assim uma medida de incentivo do poder monárquico: SMITH, C.C. The vernacular. In: ABULAFIA, D. (éd) The New Cambridge Medieval History. Vol. V. (1198-1300). Cambridge University Press, 2008, p. 80.

31 A distinção entre literatus e illitteratus não se referia à capacidade de ler ou não um texto, mas ser versado em textos religiosos ou laicos, nesse sentido, conforme Emma Campbell, os termos laicus e illetteratus eram sinônimos em alguns documentos: CAMPBELL, E. Clerksandlaity. In: GAUNT, S., KAY, S (éd). The Cambridge companion to Medieval french literature. Cambridge University Press, 2008, p. 211.

${ }^{32}$ CURTIUS, E. R. Literatura europeia e Idade Média Latina. Trad. Paulo Ronai e Teodoro Cabral. Col. Clássicos. 3 ed. São Paulo: EDUSP, 1996, p. 585-586. Passim.

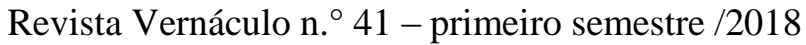

ISSN 2317-4021 
Apesar de não ser considerada uma arte superior $^{33} \mathrm{e}$ se distanciar da universidade com o fortalecimento da Teologia e da Filosofia e do método escolástico, sendo vista como "mentiras" e "fábulas vãs", ${ }^{34}$ a poesia reclamava um caráter didático, tornando-se verdade por meio da mentira. Ou seja, através de personagens míticos, símbolos e alegorias, o roman pretendia o ensino a quem escutasse nas cortes principescas. 35

Entretanto, o caráter pedagógico estava submetido a uma série de estratégias retóricas herdadas da Antiguidade (Virgílio, Estácio, Díctis e outros) como aponta Curtius. ${ }^{36}$ Desde a preferência aos versos rimados declamados no lugar de cantados como as chansons de geste, àdisposição dos versos, do ritmo da poesia, dos topoi(lugares-comuns) ${ }^{37}$ explorados evidenciando ainda a descrição e o diálogo ainda presentes nas disputatio universitárias, buscando dessa forma o ornamento

${ }^{33}$ ECO, U. Arte e beleza na estética medieval. Trad. Mario Sabino. Rio de Janeiro: Record, 2010, p.223-224. Passim.

${ }^{34}$ ZUMTHOR, P. A letra e a voz: A "literatura" medieval. Trad. Amálio Pinheiro (Parte I) e Jerusa Pires Ferreira (Parte II). São Paulo: Companhia das Letras, 1993, p. 268.

${ }^{35}$ Significado, símboloou representação eram sinônimos na Idade Média, a diferença conceitual ganha força a partir da modernidade: HANSEN, J. A. Alegoria. Construção e interpretação da metáfora. São Paulo: Atual, 1986; ECO, U. Arte e beleza na estética medieval. Trad. Mario Sabino. Rio de Janeiro: Record, 2010.

${ }^{36}$ CURTIUS, E. R. Literatura europeia e Idade Média Latina. Trad. Paulo Ronai e Teodoro Cabral. Col. Clássicos. 3 ed. São Paulo: EDUSP, 1996.

37 Em grego: comum). A teoria dos lugares-comuns é a Tópica.

Revista Vernáculo n..$^{\circ} 41$ - primeiro semestre /2018

ISSN 2317-4021 
perfeito do poema na tentativa de convencer o auditório, já que a poesia como retórica, nada mais é que uma "arte de falar". ${ }^{38}$

O Roman de Fauvel não é diferente neste aspecto. Toda as ferramentas retóricas principais disponíveis na época foram percorridas pelo poeta, que de maneira alguma pretendia a originalidade da obra e se portava apenas como um anunciador de fatos, ainda que estes fatos estivessem mascarados por símbolos. A concepção do autor visto como inventor é moderno, no medievo o autor estava associado não apenas a quem escreveu o poema, os lais, as chansons, etc., mas também para quem o interpretava e ainda quem o acompanhava com instrumentos musicais. Assim, quando falarmos em autor neste trabalho, nos referimos ao compositor e ao intérprete do Roman. ${ }^{39}$

O roman geralmente se iniciava com um incômodo do poeta em deixar omisso o conhecimento que tinha sobre o assunto e por isso desejava transmiti-lo. Dessa forma, traçava uma espécie de contrato com o auditório, pois informaria a respeito de algo desconhecido por eles. A essa tópica chamada "exordial" seguia-se inúmeras outras como a tópica da modéstia em que o poeta não se achava digno de escrever, mas que no decorrer dos versos se mostrava mestre em desenvolver o assunto; assim como era comum o poema ter um desfecho abrupto.

Para além desses recursos, o poema se valia de motivos, isto é, situações impessoais que não foram restritas em um texto com

${ }^{38}$ CURTIUS, E. R. Literatura europeia e Idade Média Latina. Trad. Paulo Ronai e Teodoro Cabral. Col. Clássicos. 3 ed. São Paulo: EDUSP, 1996, p. 103.

${ }^{39}$ ZUMTHOR, P.Introdução à poesia oral. Trad. Jerusa Pires Ferreira, Maria Lúcia Diniz Pochat e Maria Inês de Almeida. São Paulo: Editora Hucitec, 1997, p. 221.

Revista Vernáculo n. ${ }^{\circ} 41$ - primeiro semestre $/ 2018$

ISSN $2317-4021$ 
determinados personagens. É o caso do amor inalcançável de uma donzela ou de um cavaleiro que retorna à terra natal após longa viagem. Quando esses motivos tomam forma de poema, crônica, conto, etc, se tornam temas. Pires ressalta que os topoi, os lugares-comuns, são também temas, no entanto, sua especificidade se constitui em sua permanência em espaços e tempos distintos. ${ }^{40}$ É o caso das autoridades; autores de obras estudadas e debatidas nas universidades eram exploradas nos romanscomo legitimação da verdade do poeta. De maneira mais enfática a autoridade bíblica ratificava a posição do autor, assim como era a base verídica para qualquer debate no medievo. $\mathrm{O}$ Roman de Fauvel vai buscar nas Escrituras Sagradas o respaldo para sua narrativa relacionando sempre o estado atual da sociedade com a última fase da história antes do juízo final, o personagem ao Anticristo como jámencionamos, bem como a inaturabilidade das posições exercidas porFauvele pela Igreja denotando a inversão dos valores, e mais grave, da ordem estabelecida por Deus

O papa está sentado em um assento

Que fora outrora de Pedro, e que agora é de um vassalo;

Ele olha Fauvel em sua presença, A quem lhe faz grande reverência Que esfrega noite e dia $[\ldots]$

Saiba que a arca de Noé Jamais esteve em tão grande perigo,

40 PIRES, A. D. Lugares-comuns da lírica ontem e hoje. Linguagem-Estudos e Pesquisas,Catalão, vols. 12-11, p.-, 2007, p. 5.

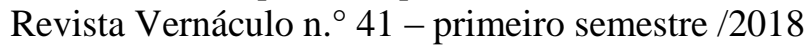

ISSN 2317-4021 
Sob os golpes poderosos de alguma vaga,

De estar submergida e destruída

Como a barca acima citada,

É a Igreja presente

Que a barca representa. ${ }^{41}$

Nos versos citados acima, o poeta lamenta a posição do pontífice outrora líder da Igreja como foi o apóstolo Pedro e, da própria Igreja representada pela arca de Noé descrita no livro de Gênesis. De Gênesis o poeta também extrai a narrativa da criação do mundo relacionando com a posição do rei e da Igreja. Esse tipo de analogia é chamada de Alegoria tipológica, dos teólogos ou in factise sua tradição remonta às epístolas de Paulo, onde os eventos e pessoas do Antigo Testamento prefiguram eventos e pessoas do Novo Testamento. Nesse sentido, o passado sempre tem uma correspondência com o presente e um pré-conhecimento do futuro, como o juízo final trazido por Deus. ${ }^{42}$

Assim, Adão, o primeiro homem criado e responsável pelo pecado da humanidade prefigura Jesus, o primeiro homem que trouxe redenção a essa mesma humanidade. ${ }^{43}$ Da mesma forma, os sacrifícios realizados no Antigo Testamento para a purificação dos pecados prefiguram o sacrifício "perfeito" de Jesus que "tira o pecado do

${ }^{41}$ Le papa se sietensonsiege, /Jadis de Pierr, or de liege; /Fuvelregardeensapresence, IA cuil'enfetgrantreverence, /Que l'ontorcheausoir et aumain;[...]Et sachiez que l'archeNoe/ Ne fu onquesen si grantdoute/ Par undenulequitantboute/D'estre noiee et desconfitel Com lanaceledessus cite, /C'est a direl'iglise presente/Que lanacele represente[..]. Roman de Fauvel, vv. 105-109, 376-382, trad. nossa.

${ }^{42}$ AUERBACH, E. Figura. São Paulo: Editora Ática, 1997, p.15.

${ }^{43}$ Cf: I Co 15: 45.

Revista Vernáculo n. ${ }^{\circ} 41$ - primeiro semestre /2018

ISSN 2317-4021 
mundo". ${ }^{44}$ Erich Auerbach, João Adolfo Hansen e Umberto Eco apontam para a frequência dessa interpretação desde a patrística, onde nosso presente está intimamente ligado ao passado bíblico. ${ }^{45}$

Tanto a alegoria dos teólogoscomo a alegoria dos poetas, (alegoria in verbis), pressupõe a correspondência explicativa no próprio poema. Dessa forma, quando Gervais de Bus lembra como Deus criou os astros sol e lua, logo em seguida ele faz a comparação com o poder monárquico e a Igreja, ainda que dê o crédito aos "sábios", retomando uma teoria elaborada pelo papa Inocêncio III (1198-1216),e portanto, outra autoridade no assunto.

Deus fez no início duas grandes tochas,

Cheias de forte e grande luz,

Mas é por diversa matéria.

Uma nomeou sol, a outra lua

Claridade de dia nos dá uma.

É o sol que ilumina o dia,

A lua de noite sem estadia.

Mas o sol, se Deus me ama,

Esteve muito mais alto no firmamento

Que a lua, que está sem dúvida,

Nem ela de claridade gosta

Que o sol nem lhe envia.

Mas Fauvel, que tudo desvia,

Tanto fez que esta luminária

Está toda invertida e ao contrário.

$[\ldots]$

${ }^{44}$ Cf: Levítico 1, Mateus 27: 35-36, João 1: 29, Hebreus 7: 26, 9:14, Apocalipse 5: 8-9, 12-13.

${ }^{45}$ HANSEN, J. A. Alegoria. Construção e interpretação da metáfora. São Paulo: Atual, 1986. AUERBACH, E. Figura. São Paulo: Editora Ática, 1997. ECO, U. Arte e beleza na estética medieval. Trad. Mario Sabino. Rio de Janeiro: Record, 2010.

Revista Vernáculo n. ${ }^{\circ} 41$ - primeiro semestre /2018

ISSN $2317-4021$ 
Os sábios que se fundam sob razão

Fazem semelhante comparação

Ao sol do céu o sacerdócio

E à lua colocada abaixo

Comparam o império temporal

A causa do que te quero dizer.

[...]

É neste sentido que Deus dirigiu o poder dos padres

Pois ele o colocou como cabeça da Igreja

E lhe quis criar o poder

De tudo ligar e desligar.

Mas à senhoria temporal

Deus não deu nenhuma soberania

[...]

Assim deve a temporalidade

Obedecer em humildade

À santa Igreja, que é dama,

Que pode ligar corpo e alma. ${ }^{46}$

Na primeira parte temos a explicação de como Deus criou o sol e a lua conforme descrito no primeiro capítulo de Gênesis, logo abaixo o próprio poeta explica como funciona a analogia com a presente sociedade e a obrigação que o poder temporal deve, isto é, o poder exercido pelo laicado ao poder exercido pela Igreja e do mesmo modo por sua cabeça, o papa, representante de Deus na Terra, já que não lhe

${ }^{46}$ Orentent, tu quiFauveltorches : /Diexfistau premier.II granstorches, /Plaines de moûttrèsgrantlumière, /Mesc'est par diversemanière. /L'une a non soleil, l'autrelune, /Clarté de journousdonnel'une : /C'estlesolailquiluist de jour, /La lune de nuitsansséjour. Meslesolail, se Diexm'ament,/ Est tropplushaut eu firmament/Que n'est lalune, c'estsansdoute, /Ne elle n'a de clarteigoûte/Que lesolail ne li envoie. /MesFauvel, quitres tout desvoie, /A tant fait que cestluminare/Est tout berstorneiaucontraire.[...] Li sagefondé sus reson/Fontsemblablecompareson/Ausolailduciel de prestrise, / Et a laluneaudessousmise/Comparenttemporelempire ; /La cause de ce te vuildire. [...] Einsidoittemporalitei/Obeïrenhumilitei/A sainteEglise, qui est dame, /Quipeutlier et corps et ame. Roman de Fauvel, vv.401-416, 423-429, 439-444,463-466,trad. nossa.

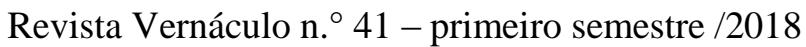

ISSN 2317-4021 
foi dado soberania como foi à Ecclesia. Em seguida o poeta afirma que embora a ordem tenha sido feita por Deus, o mundo está ao avesso graças à atuação pérfida de Fauvel.

Ora, para o ouvinte do poema ter a mesma reação de aversão ao cavalo, o poeta recorre versos antes à definição da besta. Desde o significado de seu nome à sua cor, os topoi são outros. Explora-se o bestiário medieval que atribui significado místico a cada animal relacionando-os com as ações humanas, bem como as cores. Assim, o nome Fauvel é a junção de duas palavras faus e vel (falso e véu), designando um caráter de engano escondido por um véu de sinceridade. Mas o nome de acordo com o poema também é o conjunto de seis damas formadas pelas iniciais do nome Fauvel:

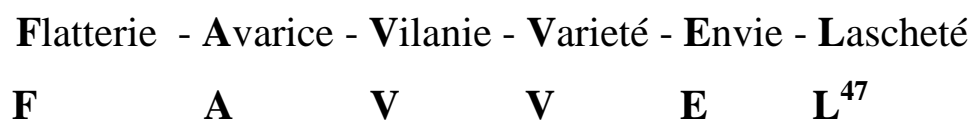

Tais damas nada mais são que Lisonja, Avareza, Vileza, Inconstância, Inveja e Covardia. Seis vícios personificados e que formam a etimologia do nome da besta, recurso muito utilizado na Idade Média, ${ }^{48}$ basta lembramos de Isidoro de Sevilha (560-636)e suas

${ }^{47}$ A letra $\mathrm{V}$ de Vilanie corresponde à letra U.

48 PASTOUREAU, M. Une histoire symbolique du MoyenÂge occidental. ÉditionsSeuil, 2004; STRUBEL, A. (Éd.,trad.) Le roman de Fauvel..Le livre de poche, 2012

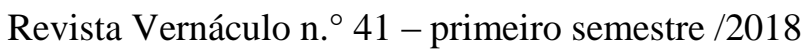

ISSN 2317-4021 
Etimologiaes. ${ }^{49}$ No segundo livro a lista de Vícios personificados é maior devido a descrição da corte de Fauvel que reúne entre outros, a Sensualidade, a Luxúria, a Inveja, a Detração e o Ódio. ${ }^{50}$ De todo modo, tudo o que se refere ao cavalo Fauvel é feito de trapaça e engano, como seu assento, as pinturas que retratam toda a história de Renard, a raposa trapaceira famosa na Idade Média, da qual Fauvel tem parentesco, ${ }^{51}$ além de sua própria cor: fauve, significando além de hipocrisia,falsidade, mentira ${ }^{52}$ a cor bege, nem branco nem preto, cor do doente. ${ }^{53}$ No roman, o poeta cita Aristóteles quando vai iniciar a descrição de Fauvel, lembrando como o filósofo afirmava que os acidentes ajudam na descoberta do ser, ou seja, as características do ser auxiliam na compreensão do que o ser é em seu interior. ${ }^{54}$

${ }^{49}$ PASTOUREAU, M. Une histoire symbolique du Moyen Âge occidental. Éditions Seuil, 2004.

${ }^{50}$ Roman de Fauvel..., vv. 1424, 1502, 1527, 1543, 1567. No Roman de la Rose os vícios e virtudes também são retratados como pessoas como o Amor e a Generosidade (Roman de la Rose, vv. 22, 1127).

${ }^{51} \mathrm{O}$ Roman de Renard está associado fundamentalmente à crítica contra as ordens franciscanas e mendicantes a partir da querela surgida na Universidade de Paris no século XIII. A raposa como animal astuto vem da tradição grega como Detienne e Vernant analisaram, mas a astúcia explorada nos mitos gregos possuía uma ética diferente da medieval, podendo ser associado ao bem ou ao mal: DETIENNE, M.; VERNANT, J-P. Métis: As astúcias da inteligência. São Paulo: Odysseus Editora, 2008. Na Idade Média a trapaça característica de Renard está agregado ao mal demoníaco. As ordens mendicantes eram acusadas de se entregarem ao vícios mundanos como a luxúria e a riqueza. Fauvel porsua vez, não influencia somente os clérigos -embora grande parte do poema aborde as ações da Igreja-, ele está presente em toda a sociedade, em todos que se deixam enganar pelos vícios.

${ }^{52}$ VAN DAELE, H. Petit Dictionnaire de l'AncienFrançais. Paris: LibrairieGarnier Frères, 1939, p. 192.

53 PASTOUREAU, M. Une histoire symbolique du MoyenÂge occidental. ÉditionsSeuil, 2004

${ }^{54}$ Roman de Fauvel..., 2012, vv. 176-178.

Revista Vernáculo n. ${ }^{\circ} 41$ - primeiro semestre $/ 2018$

ISSN 2317-4021 
Com essas informações a respeito do cavalo que no cotidiano dos séculos XI e XII poderia acompanhar o homem em batalhas ou no arado, e que agora no século XIII e XIV sua simbologia lembra os quatro cavalos apocalípticos como nos lembra Denis Hué, ${ }^{55}$ o auditório transita entre divertir-se com os versos e refletir-se sobre suas ações na sociedade, como servo de Deus ou da besta mensageira do Diabo. ${ }^{56}$

Como evidenciamos, a cada traço do Roman de Fauvel, os recursos retóricos utilizados pelo poeta eram frequentes, exceto o uso do cavalo em detrimento da raposa como personagem da narrativa. Porém, ao destacarmos alguns trechos do poema e mesmo a síntese da história de Fauvel, o conflito entre Igreja e Reino são evidentes e nesse sentido, compreender o que poderia ter motivado a produção de um poema que discutisse exatamente essa frágil relação entre poderes no fim da Idade Média, nos ajuda a compreender o próprio peso destes fenômenos no período.

${ }^{55}$ HUÉ, D. L'orgueilducheval. In: Le chevaldansle monde médieval [enligne]. Aix en Provence: Pressesuniversitaires de Provence, 1992. Disponível em <http: //books.openedition.org/pup/3331>. Acesso em: 04/jul/2016. p. 4. No livro de Apocalipse são descritos quatro cavalos cada qual com uma cor: branco, vermelho, preto e amarelo. Cada cavalo simboliza um castigo para a humanidade no fim dos tempos; de crise econômica à guerras, fome, pestes e morte. Cf. Apocalipse, cap. 6 vers. $2-8$.

56 Roman de Fauvel..., 2012, vv. 1170-1180. Cf. MÜHLETHALER, J-C. Le dévoilementsatirique. Texte et imagedansle Roman de Fauvel.Poétique, 2006/2 ( ${ }^{\circ}$ 146), p. 165-179. Disponível em<http://www.cairn.info/revue-poetique-2006-2-page165.htm>. Acesso em: 03/nov/2015, p. 166.

Revista Vernáculo n. ${ }^{\circ} 41$ - primeiro semestre /2018

ISSN 2317-4021 


\section{Poderes material e espiritual, na mão de quem?}

Diversos conflitos emergiram entre as lideranças eclesiásticas e a corte real durante o reinado de Filipe IV, o Belo (1285-1314) da França. Desde a década de 1290 disputas feudais entre o rei da Inglaterra Eduardo I e o rei da França levaram os monarcas à guerra declarada em 1294 sendo custeada com ajuda das taxas cobradas à Igreja por ambos os reis. No mesmo período, disputas entre o bispo da região de Pamiers Bernard Saisset e o conde de Foiximpeliram o papa Bonifácio VIII (1294-1303) e o rei por intermédio de seus juristas a tomarem decisões que iam de encontro às prerrogativas ora do papa, ora do monarca.

Da cobrança de taxas, inadmissível para o papa e repreendida pelas constituições apostólicas Clericis Laico (1296) e duas declarações do documento, a Abolim ante de 27 de julho de 1297 e a Etsi de statu de 31 de julho $1297 ;^{57}$ e da disputa pela região de Pamiers, a qual tanto o papa quanto o rei reclamava autoridade jurisdicional, em 1301 o jurista Pierre Flotte elabora um processo contra o bispo acusando-o de traição,

57 DIGARD, G; FAUCON, M; THOMAS, A; FAWTIER, R. Les Registres de Boniface VIII. Recueildesbulles de ce pape publiées ou analysées d'aprèslesmanuscritsoriginauxdesarchivesduVatican. t. I. Paris: Librairiedesécolesfrançaises d'Athènes et de Rome. 1884, p. 584-585, 941-944. A cobrança de taxas chamadas dízimos, em alusão ao pagamento da décima parte da renda do cristão a Deus descrita no Antigo testamento era aceita em situações de emergência como peste, fome e mesmo a guerra, mas com o devido consentimento do papa, o que não ocorreu durante a guerra entre Filipe IV e Eduardo I.

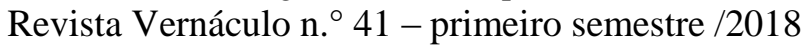

ISSN 2317-4021 
ofensas contra o rei Filipe, simonia, heresia e blasfêmias, o que resultou na excomunhão do conde de Foix por parte de Bonifácio VIII. ${ }^{58}$

A partir desse processo, outros processos foram arquitetados.

Em 1303 contra o próprio pontífice acusado de simonia, blasfêmia, heresia e idolatria, dois anos após promulgar uma constituição apostólica severa contra o rei: a Ausculta fili de 1301 e sobretudo a Unam Sanctam de 1302; em 1307 já durante o pontificado de Clemente V (1305-1314) $)^{59}$ contra a Ordem dos Pobres Cavaleiros do Templo de Salomão, até então considerada inatingível pelo poder laico, em 1309 contra o senescal de Carcasonneacusado de corrupção na administração real e simonia. ${ }^{60}$

As medidas régias desafiavam a autoridade pontifícia na medida em que conduzia os interrogatórios a membros eclesiásticos, o que por lei não era permitido, sendo reservado ao rei apenas a execução

${ }^{58}$ PACAUT, M. Histoire de lapapauté. De l'origineauconcile de Trente. Fayard, 1976, p. 272. ULLMANN, W. A Short History of the Papacy in theMiddle Ages. London: Taylor \& Francis e-Library, 2005, p. 178-179. Passim. THÉRY, J. Philippe le Bel, pape en son royaume. L'histoire, Sophia Publications, 2004, pp. 14-17. Disponível em <halshs-00219769>. Acesso em 03/ago/2016, p. 16.

${ }^{59}$ Bonifácio VIII morre em 1303 rodeado por escândalos e conflitos com a família Colonna apoiada por Guillaume de Nogaret, jurista real. As famílias Colonna e Orsini eram rivais não somente nas comunidades de Roma, mas na própria Curia. O cardeal Benoît Caetanin futuro Bonifácio VIII foi eleito em 1294 após a renúncia de Celestino $\mathrm{V}$ também com votos dos Colonna, mas as decisões tomadas enquanto pontífice multiplicaram os descontentamento por parte da família: anulação de cargos estabelecidos pelo papa anterior, nepotismo e conservadorismo, tomada de regiões e privilégios antes concedidos à família: PACAUT, M. Histoire de lapapauté. De l'origine au concile de Trente. Fayard, 1976. FAVIER, J. Philippe Le Bel. Fayard, 1978.

${ }^{60}$ THÉRY, J. Philippe le Bel, pape en son royaume. L'histoire, Sophia Publications, 2004. pp. 14-17.

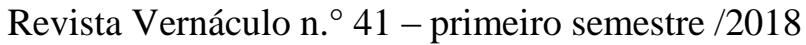

ISSN 2317-4021 
da decisão tomada pelo papa. Por outro lado, o rei legitimava suas ações através das Escrituras Sagradas ao se colocar como liderança não somente material do reino, mas também espiritual a partir do momento em que o líder da Igreja não se encontrava em condições de conduzir o povo devido seus próprios pecados. ${ }^{61}$

Em 1305 durante um encontro com Filipe IV em Lyon, cidade "recentemente integrada ao reino", Clemente V foi coroado. Devido as negociações com o rei sobre continuar o processo contra Bonifácio VIII, Clemente permanece na França até 1309, ano em que se realizou o concílio de Viena e o ano em que o papa se estabeleceu em Avinhão como uma região provisória, mas que se fixa permanentemente em 1313.A partir de então os pontífices não se instalaram mais em Roma até $1377 .^{62}$

Infelizmente não poderemos aqui discorrer sobre toda a tradição que as esferas de poder possui na história ocidental. ${ }^{63}$ Ressaltamos no entanto, que sua complexidade está presente desde as primeiras interpretações das passagens bíblicas de Pedro 2: $13-14^{64} \mathrm{e}$

${ }^{61}$ Ibidem.

${ }^{62}$ PACAUT, M. Histoire de lapapauté. De l'origineauconcile de Trente. Fayard, 1976, p 278-279. Passim. Este período ficou conhecido como Cativeiro de Avinhão ou Cativeiro da Babilônia, em alusão aos setenta anos em que o povo de Israel ficou cativo na Babilônia descrito no Antigo Testamento.

${ }^{63}$ Recomendamos: PACAUT, M. Histoire de lapapauté. De l'origineauconcile de Trente. Fayard, 1976; WATT, J. A. Pouvoirspiritueletpouvoirtemporel. In:BURNS, J. H. (Éd.) Histoire de lapensée politique médiévale. 350-1450. Éd.languefrançaise par Jacques Ménard. Presses Universitaires de France, 1993.

64 "Sujeitai-vos, pois, à toda ordenação humana por amor do Senhor; quer ao rei, como superior; quer aos governadores, como por ele enviados para castigos dos malfeitores e para louvor dos que fazem o bem"

Revista Vernáculo n. ${ }^{\circ} 41$ - primeiro semestre /2018

ISSN 2317-4021 
Mateus 16:18-19 ${ }^{65}$ durante a Alta Idade Média. Porém, como Marcel Pacaut evidencia, as lutas protagonizadas pela Igreja e pelo império e mais tarde pela Igreja e pelos reis ultrapassaram o campo teórico. Basta lembrardareforma gregoriana (século XII) em que o programa de reestruturação da Igreja intentavade maneira inevitável a reforma da própria sociedade por meio de uma cristianização ortodóxica mais intensa, bem como por meioda liberdade da Igreja sem interferência do laicado em investiduras do papa, tribunais eclesiásticos, tomada de bens, etc. No entanto, a reforma se efetivava na medida em que as decisões eram tomadas e posteriormente registradas como documentos, como a DictatusPapae de Gregório VII. ${ }^{66}$ Durante os século XIII com Inocêncio III (1198-1216) e Inocêncio IV (1243-1254) continuaram as reformas e influenciaram Bonifácio VIII sobretudo na bula UnamSanctam(1302) em que defende a sociedade, representada pela Igreja como detentora de uma única cabeça, o papa, vigário de Cristo e não possuidora de duas cabeças como um monstro. ${ }^{67}$

Quando os dois livros do Roman de Fauvelforam finalizados em 1310 e 1314, já não havia dúvidas de quem liderava o corpo

${ }^{65}$ Pois também eu te digo que tu és Pedro e sobre esta pedra edificarei a minha igreja, e as portas do inferno não prevalecerão contra ela. E eu te darei as chaves do Reino dos céus, e tudo o que ligares na terra será ligado nos céus, e tudo o que desligares na terra será desligado nos céus.

${ }^{66}$ PACAUT, M. Histoire de lapapauté. De l'origineauconcile de Trente. Fayard, 1976, p. 127-133. Passim.

${ }^{67}$ BARBOSA, J. M.; SOUZA, J. A. de C. R. de. O reino de Deus e o reino doshomens: as relações entre os poderes espiritual e temporal na Baixa Idade Média (da reforma gregoriana à João Quidort).Porto Alegre: EDIPUCRS, 1997, p. 155.

Revista Vernáculo n. ${ }^{\circ} 41$ - primeiro semestre /2018

ISSN 2317-4021 
social. ${ }^{68} \mathrm{O}$ rei foi agraciado por Deus para destruir a Ordem do Templo que estava envenenada com tantos pecados: simonia, idolatria, heresia, blasfêmia, sodomiacomo o roman aponta. ${ }^{69}$ Os últimos membros da Ordem a serem condenados e executados foram os altos dignitários Jacques de Molay, Geoffroy de Charnay e o comendador da Normandia em 1314.

Por outro lado, a Igreja e o representante de Cristo, o papa, ainda devem ser vistos como o guia das almas. No roman as posições invertidas demonstram nitidamente a inversão da ordem estabelecida divinamente. É papel da Fortuna no segundo livro esclarecer à besta que elaatua na disposição da sorte e do azar e que por isso mesmo a inversão das posições causada por Fauvel foi permissão dela e sobretudo de Deus.

O poeta recorre à Fortuna descrita por Boécio no século IV reiterando mais uma vez a autoridade acadêmica ${ }^{70} \mathrm{e}$ o topoi da roda da fortuna onde tudo está em constante mudança, nada estará sempre bem ou sempre ruim para lembrar ao ouvinte que a história já foi escrita. Deus no juízo final julgará todas as ações dos homens e em seguida o

${ }^{68}$ Uma das tradições medievais consideravam a sociedade com um corpo místico onde cada indivíduo exercia uma determinada função pré-determinada por Deus para o bom andamento do conjunto social.

${ }^{69}$ Roman de Fauvel..., 2012, vv. 277-278, 930-938, 955-959.Sobre os templários ver: HAAG, M. The templars. History \& myth. From solomon's Temple to the Freemasons, a guideto Temple History, Culture and Locations. HarperCollins Publishers Inc, 2009.

70 BOETHIUS, A, M, S. The consolation of philosophy. Trad. David R. Slavitt. Havard University Press. Cambridge, Massachusetts London, England, 2008.

Revista Vernáculo n. ${ }^{\circ} 41$ - primeiro semestre $/ 2018$

ISSN 2317-4021 
Anticristo e o Diabo, e para os fiéis a felicidade eterna está garantida; basta que o ouvinte seja um desses fieis.

Assim, o roman lembra queFortuna é apresentada como uma bela dama possuidora de duas coroas e duas rodas. Quanto às rodas que são de tamanhos distintos, elas são responsáveis pelo mundo girar, a menor que gira rápido é para os malfeitores que caem depressa e a maior que gira lentamente para a ajuda dos bons. ${ }^{71}$

No entanto, Fortuna também possui dois rostos que Fauvel enquanto se declara falsamente não consegue enxergar, mas no momento em que Fortuna começa a respondê-lo os dois são perceptíveis. $\mathrm{O}$ autor busca reunir no De consolatione, o livro mais lido depois da Bíblia e da Regra de São Bento durante a Idade Média essa dupla face. ${ }^{72}$ É também por meio da tradição de Boécio citada no texto que Fortuna elogiará não somente o filósofo, chamando-o de sábio como também a Filosofia. Mas ao descrever a ordenação do mundo, Fortuna deixa claro que ela apenas conduz o mundo, governa a partir das escolhas feitas pelo homem:

\title{
E, também como eu disse, eu conduzo A esfera do céu mais soberano. \\ De sorte que por mim são dispostos
}

\begin{abstract}
${ }^{71}$ Roman de Fauvel, 2012, vv. 2717- 2774. A primeira coroa de aparência boa contém espinhos em seu interior embora não se perceba, machuca quem a usa. A outra parece vil e suja, mas interiormente possui esmeraldas verdes. Fortuna explica que a primeira é usada por quem está preso às aparências dos prazeres mundanos, a segunda é a dos pobres que esperançosos aguardam a justiça de Deus.

${ }^{72}$ GILSON, E. A Filosofia na Idade Média. Trad. Eduardo Brandão. São Paulo: Martins Fontes, 1995.
\end{abstract}

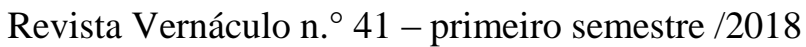

ISSN 2317-4021 
Todas as coisas do mundo nascidas

Pois planetas, sol e lua,

O céu e estrela cada uma

Têm por mim, verdadeira sentença,

Grande virtude por sua influência

Sobre as coisas embaixo, da terra,

De modo que umas se são miseráveis,

$\mathrm{E}$ as outras ricas e belas,

Segundo o giro das minhas rodas,

Com o olhar dos planetas,

De quem para umas são meigas,

E as outras ásperas e duras,

Segundo suas diversas naturezas,

Que ele [Deus] influencia

diversamente... ${ }^{73}$

Neste ponto, a ordenação do universo chamado de Macrocosmo na narrativa, é o centro da explicação da superioridade divina. No primeiro livro o fio condutor se fecha nas relações sociais dos homens, aqui percebemos uma anterioridade dessa disposição terrena pelo domínio de Deus sobre o mundo para então transpor essa dominação nas escolhas do homem e das consequências por elas produzidas, isto é, o destino final da humanidade após o fim do mundo.

A personagem Fortuna enfatiza que garantiro movimento no mundo faz parte de sua responsabilidade até que chegue ao seu fim

73 "Et, aussi com j'édit, jemaine/L'espèreducielplussouvraine./Si que par moysontdisposées/Toutezchosezdu monde neez; /Carplanetez, soleil et lune,/Le ciel et estellechescune/Ont par moy, c'estvraiesentence,/Grant vertu par leurinfluence/Surleschosez de terre bassez,/Si que lesunez si sontlassez,/Et lesautresrichez et bellez, /Selonle tour de mesroelez,/Avecleregartdesplanetez,/De quoilesunezsontdoucetez,/Et lesautresaspres et durez,/Selonleurdiversesnaturez,/Qu'ilinfluentdiversement". Roman de Fauvel..., 2012, vv. 2545- 2561, trad. nossa.

Revista Vernáculo n. ${ }^{\circ} 41$ - primeiro semestre /2018

ISSN 2317-4021 
determinado por Deus. ${ }^{74}$ Dito de outro modo, ela nada mais é que a Providência divina, também chamada de Destino, Aventura e Fortuna ${ }^{75}$ Ela é filha de Deus que criou o mundo com Sabedoria (Sapience) ${ }^{76}$ sua filha mais nova. Mas cabe aos homens traçar o destino aprazível através da obediência às autoridades temporais e espirituais, da humildade, do sofrimento, da paciência e da esperança durante sua vida na terra. Pois, os bens que os aguardam no futuro não são perecíveis.

O poeta demonstra por fim através da fala de Fortuna, a real natureza de Fauvele que ele também faz parte de um plano maior e obedece por sua vontade ou não, uma lei superiordeterminada por Deus, o julgamento final, pois ele é a personificação do mal, mensageiro doAnticristo, ligação direta com o Diabo $^{77}$ retomando a os últimos versos do primeiro livro. Assim, é necessário que Fauvelreine por mais um tempo até que ele, seu pai (o Diabo), e todas as pessoas que o seguiram sejam condenados. ${ }^{78}$

O roman termina com a proposta de Fortuna aceita por Fauvel para que ele se case com Vã Glória que fica aos pés de sua Roda. Há

${ }^{74}$ Ibidem, vv. 2233-2250.

${ }^{75}$ Ibidem, vv. 2254-2286.

${ }^{76}$ Ibidem, vv. 2201- 2211.

${ }^{77}$ Ibidem, vv. 3121 - 3127. Na Bíblia o Anticristo aparecerá na Terra antes da segunda vinda de Jesus, efetuando sinais para enganar a humanidade e se opondo a toda noção de Deus para que acreditem que o melhor provém do Anticristo que na verdade é enviado pelo Diabo. Cf. II Tessalonicenses: 2: 1-17.

${ }^{78}$ Roman de Fauvel...2012, vv. 3139- 3148.

Revista Vernáculo n. ${ }^{\circ} 41$ - primeiro semestre /2018

ISSN $2317-4021$ 
um suntuoso casamento e pouco depois a multiplicação de faveaux, filhos de Fauvel para a destruição do jardim de França, o reino francês.

Podemos observar que o poeta ao criticar a sociedade com todos os seus erros e vícios oscila entre a amargura da situação que presencia, tentando mostrar ao auditório a verdadeira face de Fauvel e dos homens, e, a esperança de um futuro já estabelecido. Apesar do diálogo com a fé, o poema atua como texto político ao buscar nos eventos contemporâneos os argumentos necessários para o desenvolvimento de sua narrativa ao mesmo tempo que se apropria de elementos retóricos consagrados como os topoipara divertir o público, sempre transitando entre a reflexão e a diversão, sendo a reescritura de lugares-comuns, símbolos e autoridades juntamente a maneira possível do poeta exercer uma criatividade na literatura durante a Idade Média, embora não a buscasse como objetivo artístico.

\section{Considerações finais}

Mais que compararmos versos e fatos políticos entre o Roman de Fauvel e o reinado de Filipe IV, o Belo, procuramos neste trabalho através da leitura literária e histórica alegórica esboçar algumas considerações acerca do roman escrito no início do século XIV que compartilha com outros registros de expressão ${ }^{79}$ não apenas instrumentos retóricos para compor histórias e canções que divertissem

${ }^{79}$ MÜHLETHALER, J-C. Le dévoilementsatirique. Texte et imagedansle Roman de Fauvel. Poétique, 2006/2 (n 146), p. 165.

Revista Vernáculo n. ${ }^{\circ} 41$ - primeiro semestre /2018

ISSN 2317-4021 
o auditório, mas por meio de uma interpretação da própria História justificavam a elaboração de suas obras, alicerçados sobre uma base forte de autoridade acadêmica como Boécio ou mais crível ainda, de autoridade bíblica.

Por isso a grande recorrência de comparações entre a sociedade contemporânea e um passado registrado nas Escrituras que prefigurem esse presente e dando uma certa segurança acerca do que o futuro reserva porque também registrado, o que podemos ver por meio da comparação entre os astros sol e lua e Igreja e reino.

Além da interpretação tipológica de longa tradição, outras ferramentas ajudavam os homens e mulheres a interpretarem seu mundo: os nomes, as cores e os animais são apenas alguns dos elementos imbuídos de significados no medievo e que se acreditava poder conhecer a essência do ser, aprendizado vindo de Aristóteles e também abordado no Roman de Fauvel.

Por fim, tentamos mostrar embora também de maneira sucinta, que o Roman de Fauvel e por conseguinte outros romans como o Roman de La Rose e o Roman de Renard, além de outros registros lúdicos tinham em comum a comunicação de técnicas: retórica, teológica, política e histórica, não podendo ser isolados pelo pesquisador.

Revista Vernáculo n. ${ }^{\circ} 41$ - primeiro semestre /2018

ISSN 2317-4021 


\section{Fontes:}

DIGARD, G; FAUCON, M; THOMAS, A; FAWTIER, R. Les Registres de Boniface VIII. Recueildesbulles de ce pape publiées ou analysées d'aprèslesmanuscritsoriginauxdesarchivesduVatican. t. I. Paris: Librairiedesécolesfrançaises d'Athènes et de Rome. 1884.

Le roman de Fauvel. Édition, traductionetprésentation par Armand Strubel. Le livre de poche, 2012.

\section{Referências:}

AUERBACH, E. Figura. São Paulo: Editora Ática, 1997.

BOETHIUS, A, M, S. The consolation of philosophy. Trad. David R. Slavitt. Havard University Press. Cambridge, Massachusetts London, England, 2008.

CAMPBELL, E. Clerks and laity. In: GAUNT, S., KAY, S (éd). The Cambridge companion to Medieval french literature. Cambridge University Press, 2008.

CERTEAU, M. A Escrita da história/Michel de Certeau; tradução de Maria de Lourdes Menezes;revisão técnica [de] Arno Vogel. - Rio de Janeiro: Forense Universitária, 1982.

CURTIUS, E. R. Literatura europeia e Idade Média Latina. Trad. Paulo Ronai e Teodoro Cabral. Col. Clássicos. 3 ed. São Paulo: EDUSP, 1996.

DETIENNE, M.; VERNANT, J-P. Métis: As astúcias da inteligência. São Paulo: Odysseus Editora, 2008.

ECO, U. Arte e beleza na estética medieval. Trad. Mario Sabino. Rio de Janeiro: Record, 2010.

DILLON, Emma. Medieval Music-Making and the Roman de Fauvel. New Perspectives in Music History and Criticism. Cambridge and New York: Cambridge University Press, 2002

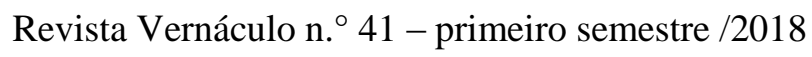

ISSN 2317-4021 
FAVIER, J. Philippe Le Bel. Fayard, 1978.

GILSON, E. A Filosofia na Idade Média. Trad. Eduardo Brandão. São Paulo: Martins Fontes, 1995.

GINZBURG, C. Mitos, emblemas, sinais: morfologia e história. Trad. Federico Carotti. São Paulo: Companhia das Letras, 1989.

HAAG, M. The templars. History\&myth. From solomon's Temple to the Freemasons, a guideto Temple History, Culture and Locations. Harper Collins PublishersInc, 2009.

HANSEN, J. A. Alegoria. Construção e interpretação da metáfora. São Paulo: Atual, 1986.

. A sátira e o engenho. Gregório de Matos e a Bahia do século XVII. São Paulo: Companhia das Letras: Secretaria do Estado da Cultura, 1989.

HUÉ, D. L'orgueilducheval. In: Le chevaldansle monde médieval [enligne]. Aix en Provence: Pressesuniversitsaires de Provence, 1992. Disponível em <http: //books.openedition.org/pup/3331>. Acesso em: 04/jul/2016. p. 257276.

MAURICE, J.Une satire contre Philippe le Belet Clément V. In: Bibliothèque de l'école des chartes. 1908, tome 69. pp. 280-281. Disponível em:

http://www.persee.fr/web/revues/home/prescript/article/bec_03736237_1908_num_69_1_448336>. Acesso em: 30/abr/2017.

MÜHLETHALER, J-C. Fauvelaupouvoir. Lirelasatiremédiévale. Paris:Champion (Nouvelle bibliothèqueduMoyenÂge, 26), 1994.

. Le dévoilementsatirique. Texte etimagedansle Roman

de

Fauvel.

Poétique2006/2 (n ${ }^{\circ}$ 146), p. 165-179. Disponível

Revista Vernáculo n. ${ }^{\circ} 41$ - primeiro semestre /2018

ISSN 2317-4021 
em<http://www.cairn.info/revue-poetique-2006-2-page-165.htm>. Acesso em: 03/nov/2015.

PACAUT, M. Histoire de lapapauté. De l'origineauconcile de Trente. Fayard, 1976.

PASTOUREAU, M. Une histoire symbolique du MoyenÂge occidental. ÉditionsSeuil, 2004.

PIRES, A. D. Lugares-comuns da lírica ontem e hoje. Linguagem-Estudos e Pesquisas,Catalão, vols. 12-11, p.-, 2007.

SHEN-WEI, T.H. Musical "Beastliness" in the Roman de Fauvel(BN fr. 146): Chaillou's "addicions" and Sensory Danger. 2010. 233p. Tese (DoutoradoemMúsica). The Honors College, Wesleyan University, 2010.

SMITH, C.C. The vernacular. In: ABULAFIA, D. (éd) The New Cambridge Medieval History. Vol. V. (1198-1300). Cambridge University Press, 2008.

THÉRY, J. Philippe le Bel, pape en son royaume. L'histoire, Sophia Publications, 2004, pp. 14-17. Disponível em <halshs-00219769>. Acesso em 03/ago/2016.

ULLMANN, W. A Short History of the Papacy in theMiddle Ages. London: Taylor \& Francis e-Library, 2005.

VAN DAELE, H. Petit Dictionnaire de l'AncienFrançais. Paris: LibrairieGarnier Frères, 1939.

WATT, J. A. Pouvoirspiritueletpouvoirtemporel. In:BURNS, J. H. (Éd.) Histoire de lapensée politique médiévale. 350-1450. Éd. languefrançaise par Jacques Ménard. PressesUniversitaires de France, 1993.

ZUMTHOR, P. A letra e a voz: A "literatura" medieval. Trad. Amálio Pinheiro (Parte I) e Jerusa Pires Ferreira (Parte II). São Paulo: Companhia das Letras, 1993.

Revista Vernáculo n. ${ }^{\circ} 41$ - primeiro semestre /2018

ISSN $2317-4021$ 
. Introdução à poesia oral. Trad. Jerusa Pires Ferreira, Maria Lúcia Diniz Pochat e Maria Inês de Almeida. São Paulo: Editora Hucitec, 1997.

Recebido em 01/06/2017, aceito para publicação em 26/07/2017.

Revista Vernáculo n. ${ }^{\circ} 41$ - primeiro semestre /2018 ISSN 2317-4021 